\title{
\begin{tabular}{l} 
helms, Mary w. 1996. "Color and Crea \\
\hline \hline http://www.jstor.org/stable/20166955
\end{tabular}
}

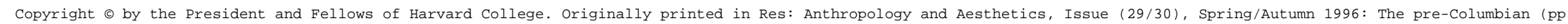

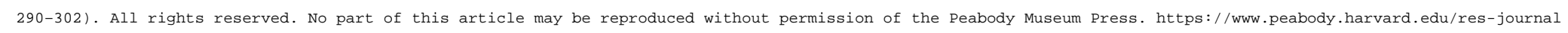

290 RES 29/30 SPRING/AUTUMN 1996

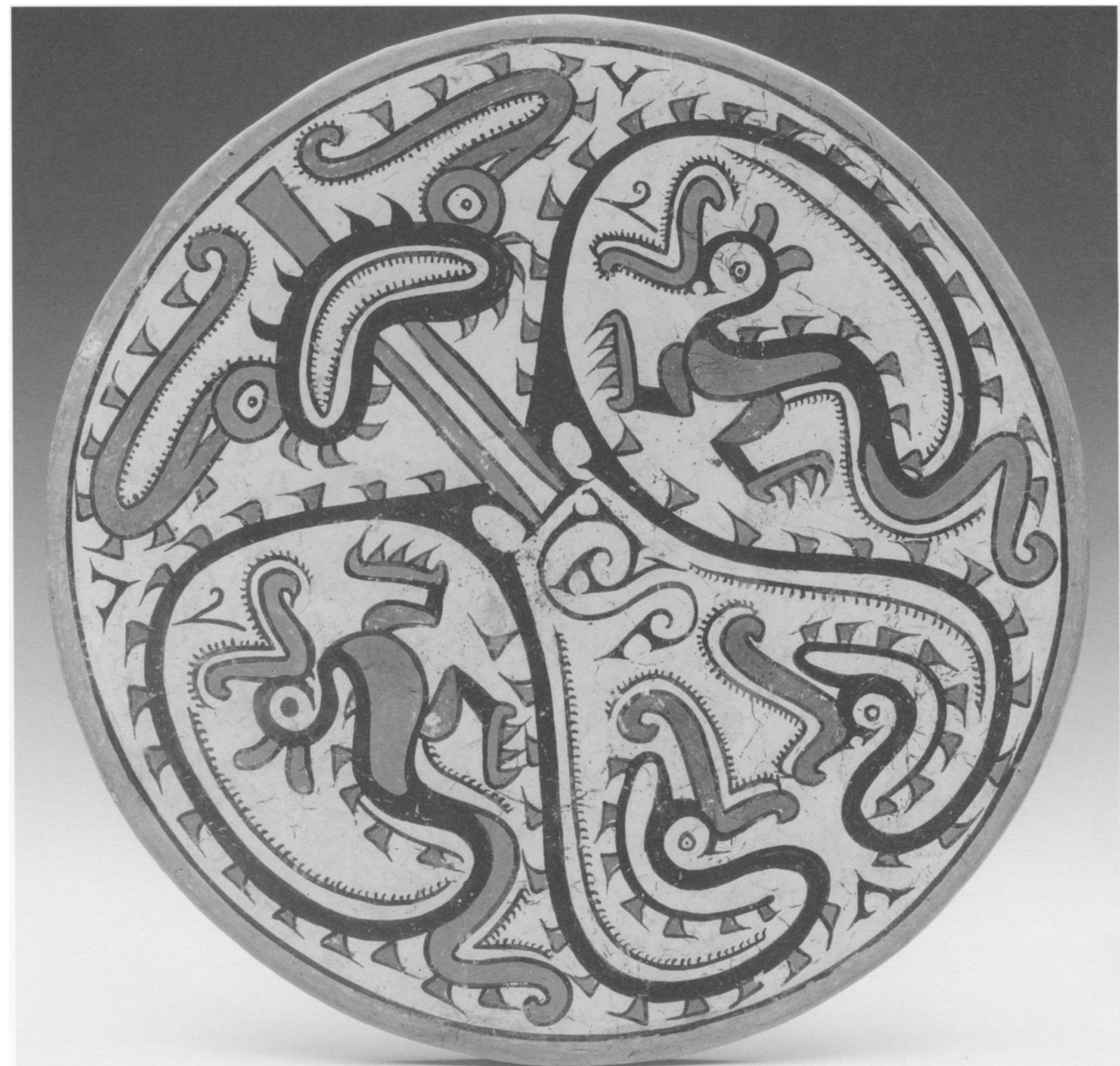

Figure 1. Ceramic pedestal bowl, Conte style, Panama A.D. 600-800. $31.7 \times 4.12 \mathrm{~cm}$. Private collection. Courtesy of private collector. Photo: 1991 Douglas M. Parker.

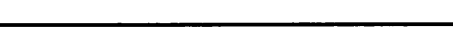




\title{
Color and creativity
}

\section{Interpretation of themes and design styles on a Panamanian Conte bowl}

\author{
MARY W. HELMS
}

\begin{abstract}
To "outsiders" from the Western industrial world, indigenous art constitutes one of the most fascinating and enticing avenues into the conceptual worlds of indigenous peoples. This is certainly true for pre-
\end{abstract} Columbian societies of the Americas, where artistry in stone, bone, wood, shell, ceramics, and metal encodes aspects of cosmologies and political ideologies that can greatly enhance both our intellectual understanding and our aesthetic appreciation of these ancient societies, provided we can "decode" the often enigmatic (to us) signs and symbols such sophisticated art portrays.

The colorful ceramic art associated with the ranked and centralized polities (chiefdoms) that had become established in Panama by at least A.D. 500 and continued to exist, with various modifications, until the European conquest, is a case in point (Cooke 1984; Helms 1979). Various types of vessels, including effigy forms, trays, plates, bowls, carafes, and jars, were preserved by burial in caches or interments of the political elite. The vessels were elaborately painted often in complex geometric and curvilinear polychrome designs that have been interpreted in various ways by a number of scholars (Helms 1995; Labbé 1995; Linares 1977; Lothrop 1942). In general, however, Panamanian ceramic art is not yet as well known or as thoroughly analyzed as artforms from neighboring cultures of the Andes or Mesoamerica. Consequently, the underlying intent of this article is to contribute to a growing awareness of the richness and depth of the symbolism of Panamanian polychrome art by discussing the designs painted on the interior surface of a pedestal plate decorated in the Conte (or Early Coclé) style (Cooke 1985) from ca. A.D. 600-800 (fig. 1). Because this depiction is particularly rich, discussion of themes and design styles portrayed on this vessel can serve nicely as a general introduction to a number of distinctive motifs characteristic of ancient Panamanian ceramic art in general. Detailed consideration of this piece, even though interpretations obviously must remain tentative at this very preliminary stage of our understanding of ancient Panamanian art, can help to sharpen our awareness of the complexity of Panamanian ceramic designs and can help us "see" them better. ${ }^{1}$

In general, I have found the most useful guidelines for insight into the possible "meanings" encoded in Panamanian ceramic art are formulated by viewing these designs as a semiotic code expressing sociological and especially cosmological concepts that also had some bearing on the political ideology that legitimized authority. I have also found many helpful ideas and suggestions in the exegesis of the mythology and symbolism of present-day indigenous peoples of Central America and tropical South America in spite of the many centuries that separate these societies temporally from the pre-Columbian Panamanian world. Research into the "world views" of these and other native American cultures has shown that traditional art provides tangible expression of indigenous conceptualizations of the nature of the cosmos and the place of human society, and especially society's leadership, therein (for example, Rabineau 1975; Schele and Miller 1986; Whitten and Whitten 1988). I believe that the polychrome ceramic art of ancient Panama was intended to convey the same type of information.

When figure 1 is viewed directly, one of the most obvious features of the design portrayed is the use of several colors-black, dark red, and brown (fig. 2; see color illustration in Helms 1992:227). Closer observation reveals that the colors identify and differentiate significant design units and presumably

1. In discussing these topics, however, it will not always be possible, in the space allotted, to provide a full explanation as to why a particular interpretation is chosen and/or to completely explore all the ramifications of the various constructions Interested readers are therefore encouraged to consult the more detailed discussions of Panamanian ceramic art in longer monographs written by myself (Helms 1995), Armand Labbé (1995), Olga Linares (1977), and Samuel Lothrop (1942) both for fuller elaboration of topics discussed here and for information on additional design motifs characteristic of Panamanian polychrome ceramics. These several monographs also approach interpretation from somewhat differing perspectives, but all concur in recognizing a rich symbolism broadly related to political and ideological rank and status. 

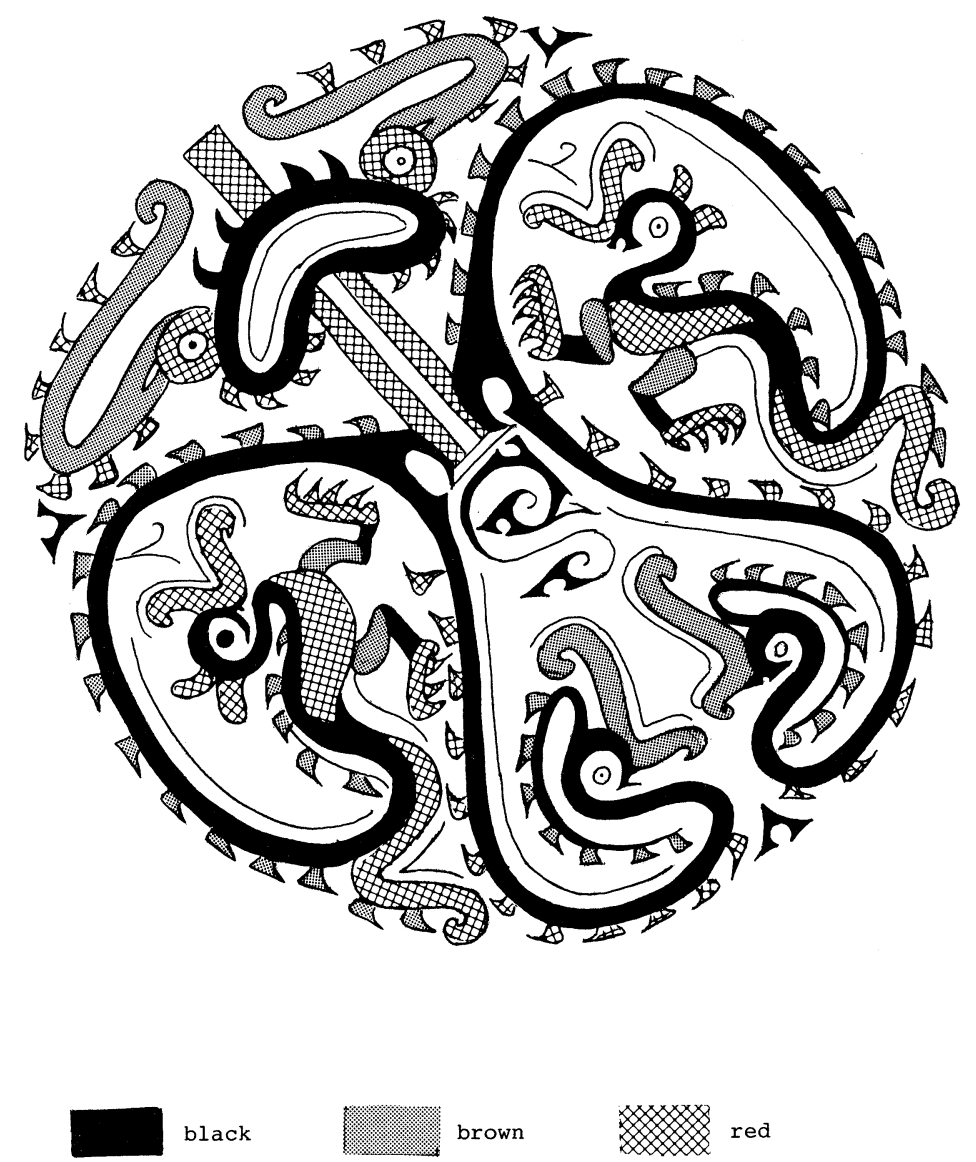

Figure 2. Figure 1 design color-coded. Drawing: Mary Helms.

accompanying themes. For example, I propose that the manner in which black was used in this design (other than general outlining) ${ }^{2}$ signifies a fundamental serpentine quality or "presence" that imbues the large, bipedally stanced upright creature that is the major design feature (fig. 3). This identification is based on several factors: (1) the sinuous, serpentine nature of the

2. The manner in which color is used appears to be unique to each ceramic piece, where polychrome differentiates among constituent design units. There does not appear to be any consistent use of a particular color to designate a particular motif in Panamanian art in general. That is to say, serpents are not always black or deer red, etc. The immediate intent seems to be to create visual contrasts in each design that define its constituent units and thus convey significance. The use of multiple colors overall, and especially the use of solid blocks of color with well-defined borders, however, may be intended to signify the general concept of cosmological order (LéviStrauss 1969:280, 325; Helms 1995:chap. 1). upper and lower limbs drawn in black, ${ }^{3}(2)$ the shape of the open mouth, also rendered in black, which is in accord with mouth forms of serpents and serpentrelated creatures in other depictions of Conte (Coclé) designs (Lothrop 1976:frontispiece, 41 [top left], 42 [lower right], 26 [top left], 27 [top]) (fig. 4), (3) the fact that the other features of the image are depicted as appendages of the basic black form, (4) the evidence discussed at length in Helms (1995:chap. 2) regarding the virtually ubiquitous presence of serpent motifs and serpent-related themes in Panamanian art in general, and (5) the stylistic means of executing these motifs.

3. In other related designs, the serpent theme is depicted on limbs by means of a kenning composed of alternating sets of horizontal and vertical parallel lines representing serpent, especially boa, markings. See Helms (1995:20-21, fig. 10). 
In naturalistic terms, judging from markings on certain other ceramic designs not found on figure 1 (Labbé 1995:fig. 40; Lothrop 1976:55 [bottom]), I believe that whenever the serpent is portrayed in ancient Panamanian art it can be identified as the boa constrictor unless there is definite evidence otherwise (Helms 1995:18-20). Ecologically, the boa constrictor is the large constrictor serpent of the Isthmus as the anaconda is for Amazonia. In cosmological or mythical terms, the Panamanian serpent can be understood as the Isthmian version of the Great Snake or Rainbow Serpent that is widespread in indigenous American mythology and symbolism. The creative and transformative roles attributed to the Amazonian anaconda as mythical Great Serpent and the vision serpent of the Classic Maya, with its theme of other worldly communication and transformation, are wellknown parallels (Helms 1995:11-13, 19-20, 105-106; Roe 1989; Schele and Miller 1986:46-47, 177, 187-188).

The color red, as used in figure 1 , identifies the mouth, small rounded ears, main body form, long tail, and clawed feet of the two "side" animals, which, judging especially from the shape of the ears, appear to be mammals (fig. 5 ). In other words, red identifies distinctly mammalian features as "appendages" (mouth, ears, tail, claws, rounded trunk) attached to a fundamentally serpentlike form indicated by the black curvilinear line (the "arm" of the central figure) that forms the rounded head and the curve of the neck and back as well as the lower portions of the legs of the two side mammals (fig. 2). Red and black together may identify the two side creatures as mammals (red) imbued with the elemental dynamic of movement and energy that signifies the presence of life force - expressed by the concept of the serpent (black)-in a living form.

In comparable fashion, red is also used to define the "physical" features of the head of the main creature by delineating eyes, a distinctive neck, and what is probably a head-crest (compare with the profiled head shown in Lothrop 1976:44 [lower right]; see fig. 6), all of which are depicted as "appendages" to the open serpent mouth. Here again, I believe that the intent is to define the central figure as a physically distinctive being (red) imbued with the quality of serpentness (black) or, perhaps better said, as a manifestation of cosmological serpentness in a distinctive guise.

The color brown delineates the "streamers" emanating from the eyes of the central figure, the upper portion of the limbs of the side mammals, and the open mouths that also define both the "feet" of the central

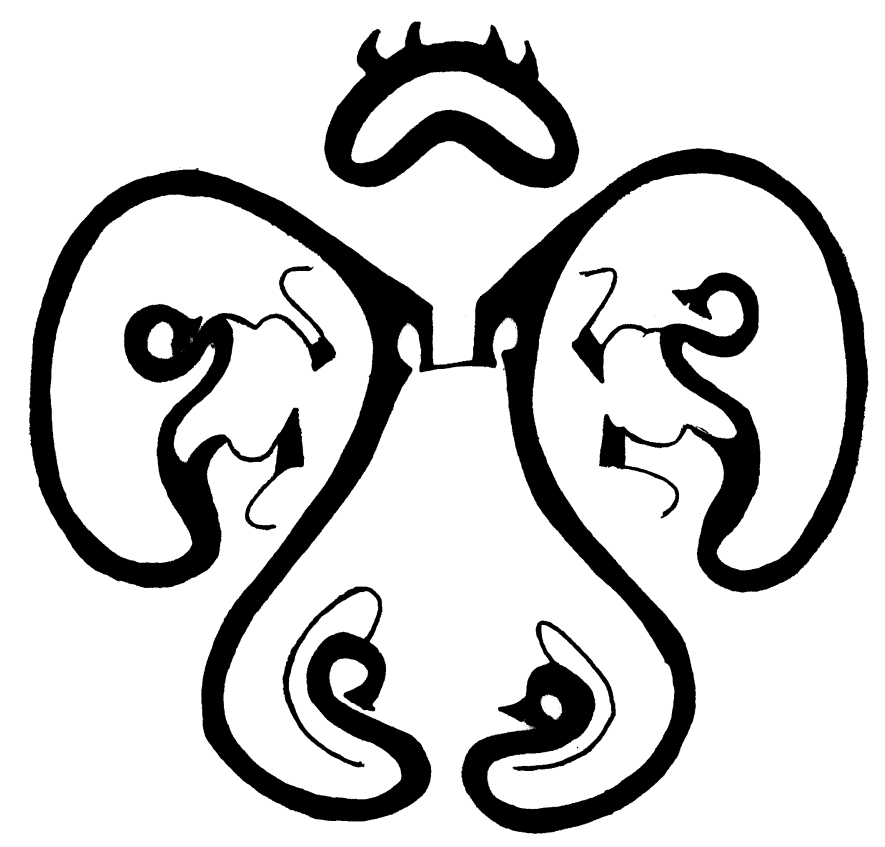

Figure 3. Use of the color black in figure 1 design. Drawing: Mary Helms.

figure and its female gender (fig. 7). A general interpretation concerns the theme of luminosity, including things that glisten or have luster or sheen, such as the eyes, whose brightness, gleam, or "flash" might be expressed by the depiction of streamers. ${ }^{4}$ In addition, as configured in figure 1 (see also Labbé 1995:fig. 4; Lothrop 1976:42 [center left]) these streamers may also imply a headdress (see figs. 8-9 below) which, in physical form, would have been composed of iridescent feathers (Kensinger 1991:43). With respect to the foot-end of the central figure, glistening luminosity could be associated with the physical nature of mammalian sexuality in female reproductive organs and, by extension, with the processes of birth. ${ }^{5}$ (Conceivably the brown coloration in the upper portion of the limbs of the two side mammals refers to the iridescent quality of fur.)

4. See Lothrop (1976:41 [top left], 59 [top]) It is noteworthy that the boa is also characterized by a distinctive dark postorbital streak along both sides of the head.

5. See Lévi-Strauss (1979:320-323) for an interpretation of a Panamanian (Kuna) incantation used by religious specialists to facilitate difficult childbirth which describes both physical processes and supernatural spirits that are either implied or explicitly described as being shining or gleaming in nature and as "lighting up" the uterine world involved. 


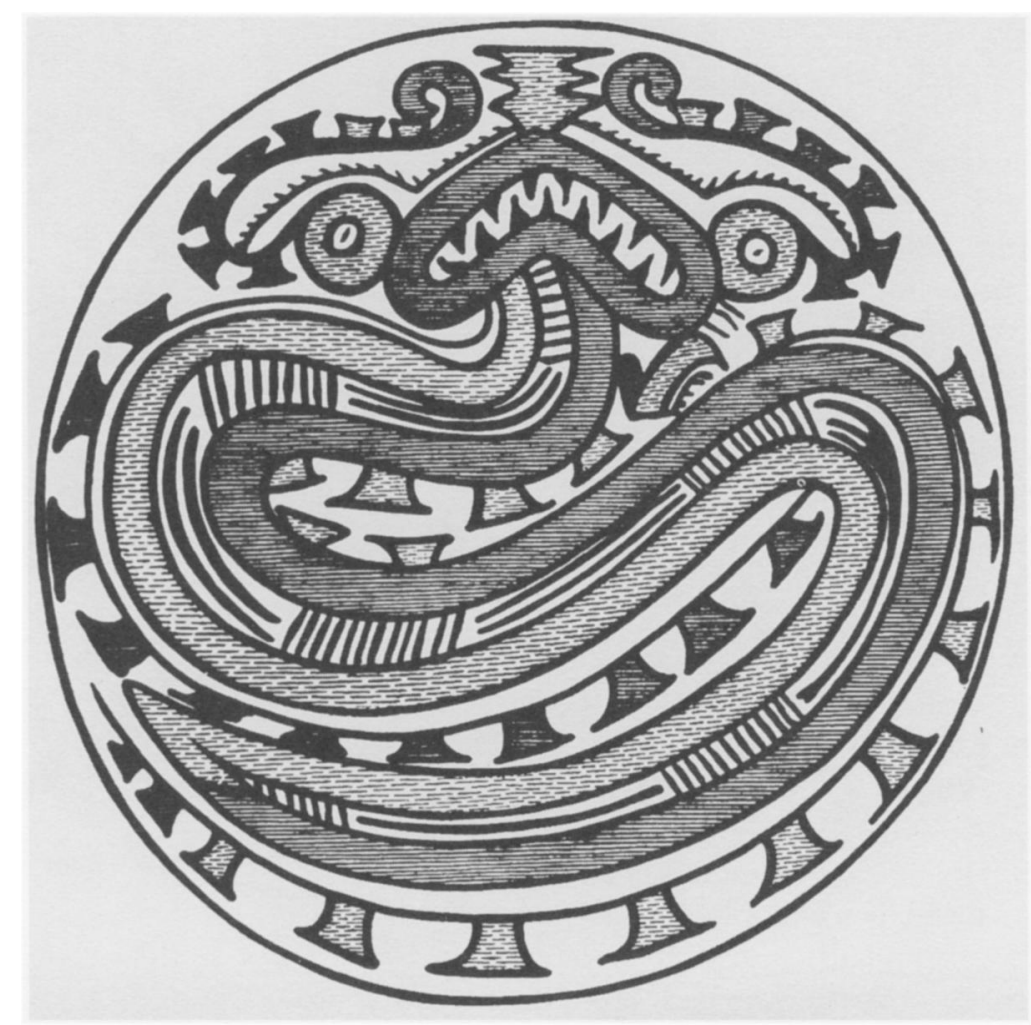

Figure 4. Serpentine design on Sitio Conte bowl with head form comparable to figure 1. From Samuel K. Lothrop, Pre-Columbian Designs From Panama (Dover Publications, 1976), p. 41 (top left). Courtesy of Dover Publications.

Iridescence or, better said, luminescence in general is a widely recognized aesthetic quality referring to celestial phenomena, light, brightness, the presence of supernatural energy, vitality, health, well-being, and/or creative ancestral origins (Helms 1995:99-101; Morphy 1989; Roe 1989:13-14). Among the Kogi of the Sierra Nevada de Santa Marta in northern Colombia (to take one example that is of particular interest because of the proximity of the Kogi and their mountains to Panama and because of its reference to light, sight, and female sexuality), when Indians walk on the high páramos, the sacred abode of the Great Mother (see below), they avoid looking at the numerous glacial lakes that dot the landscape, partly because these lakes are the openings of Great Mother's body and partly because travelers often perceive a brilliant flash of the sun's reflection on the lakes. This reflection, which can suddenly strike the eye, is compared with certain luminous sensations that may be received under the influence of drugs when a brilliant light, believed to be a direct manifestation of a divine being, is sometimes perceived and is accompanied by visions. In the ultimate priestly revelation experienced high in the mountains, such a flash of light connects sight and sex, for at the instant of hallucinatory illumination, the flash of light reveals the sexual organs of the Great Mother (Reichel-Dolmatoff 1978:24-25). ${ }^{6}$

Let us now consider other features of the overall design on figure 1 , beginning with the main figure that is portrayed as a frontal, upright, bipedal creature with upper limbs extended to either side. This composition essentially divides the plate into quadrants containing a head-end $(A)$, lower limbs $(C)$, and identical "side"

6. It is also interesting to note that, according to Samuel Lothrop, who excavated a number of Coclé polychrome ceramics at the Sitio Conte in central Panama in the 1930s, the ceramic pieces were originally coated with a kind of varnish, probably a vegetal compound, that imparted a shiny, luminous surface to them and their designs (1942:12) Unfortunately, this fragile coating could not be preserved during excavation. 


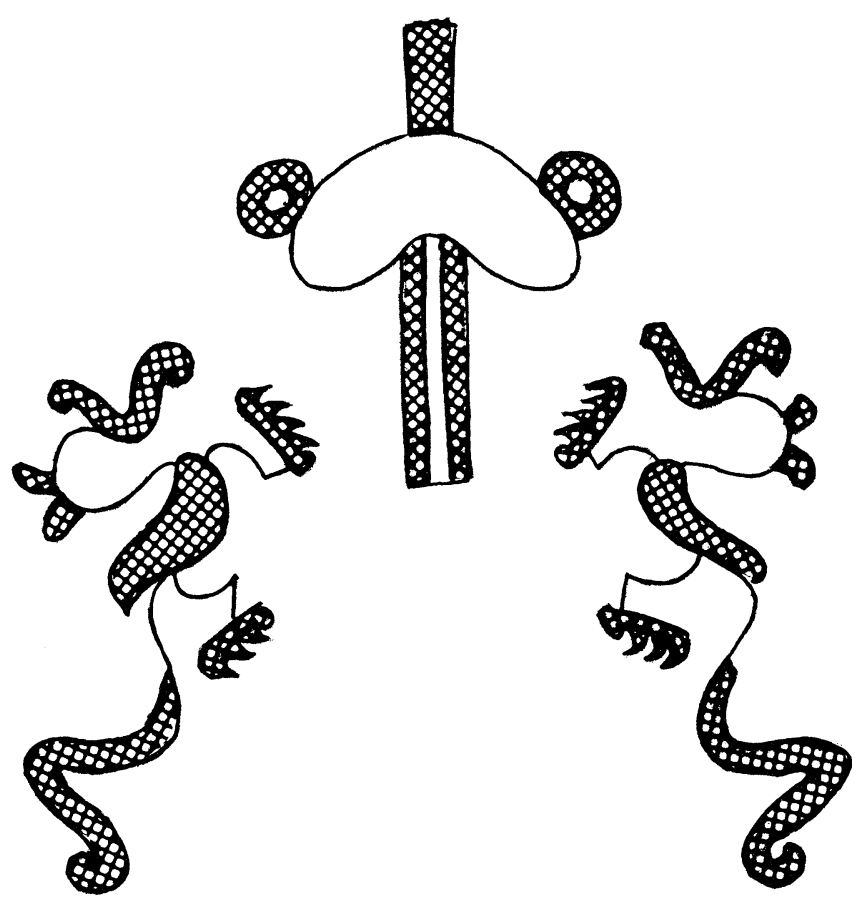

Figure 5. Use of the color red in figure 1 design. Drawing: Mary Helms.

elements (B and B) (fig. 10). This format is characteristic of a number of other ceramic plate designs (for example, Helms 1995:95-96; Labbé 1995:fig. 73; Lothrop 1976:5 [top right], 14 [bottom left]) as well as the design on several embossed gold chestplates (figs. 8-9) that also portray a similar creature with outstretched arms, wide headdress, and animals affixed to either side of the waist (belt) of the central figure, as a hunter carrying game. This overall design suggests the theme of the "belted hunter," also a culture hero, who appears in myths from Amazonia (Helms 1977; LéviStrauss 1969:36) and/or of a Master of Animals (Helms n.d.). Both motifs may ultimately refer to a more fundamental type of original creator being somewhat comparable to the Great Father, the principal deity of the contemporary Kuna Indians of northeast Panama (though possibly reflecting some degree of missionary influence). The Kuna "Father" created the world, sent civilizing culture heroes to instruct the people on how to maintain social and moral order, and still watches over it (Howe 1986:36, 58).

The main figure in figure 1 , therefore, may be initially related, in part, to such mythemes, at least as

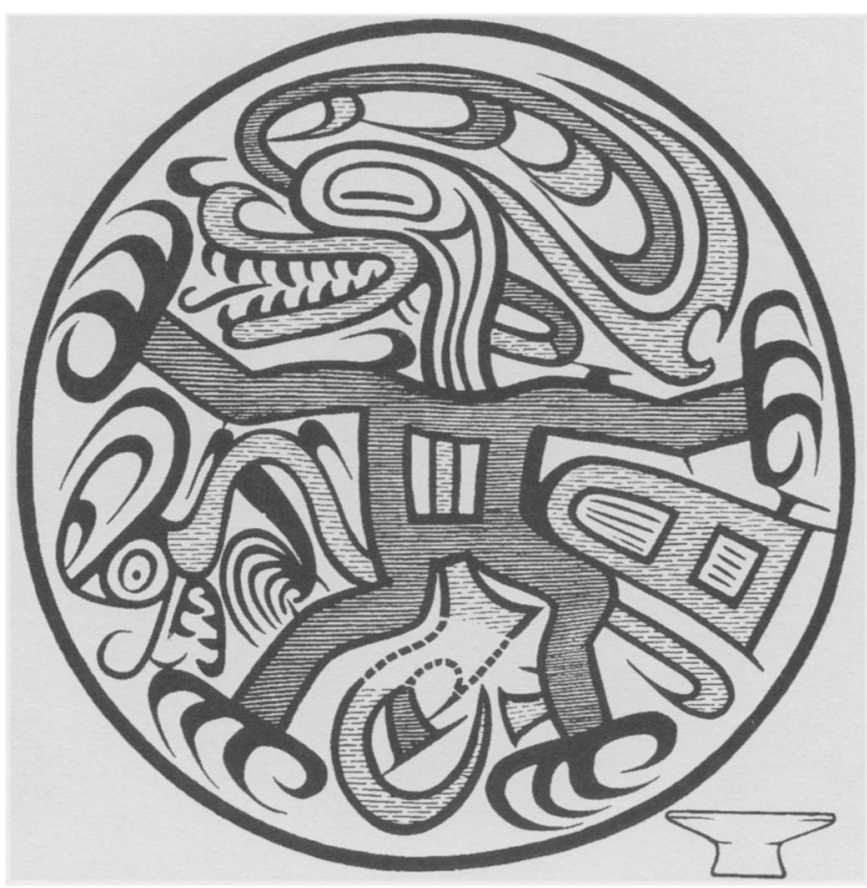

Figure 6. Four-limbed, bipedal-stanced creature with profiled head and headdress suggestive of figure 1. From Samuel K. Lothrop, Pre-Columbian Designs From Panama (Dover Publications, 1976), p. 44 (lower right). Courtesy of Dover Publications.

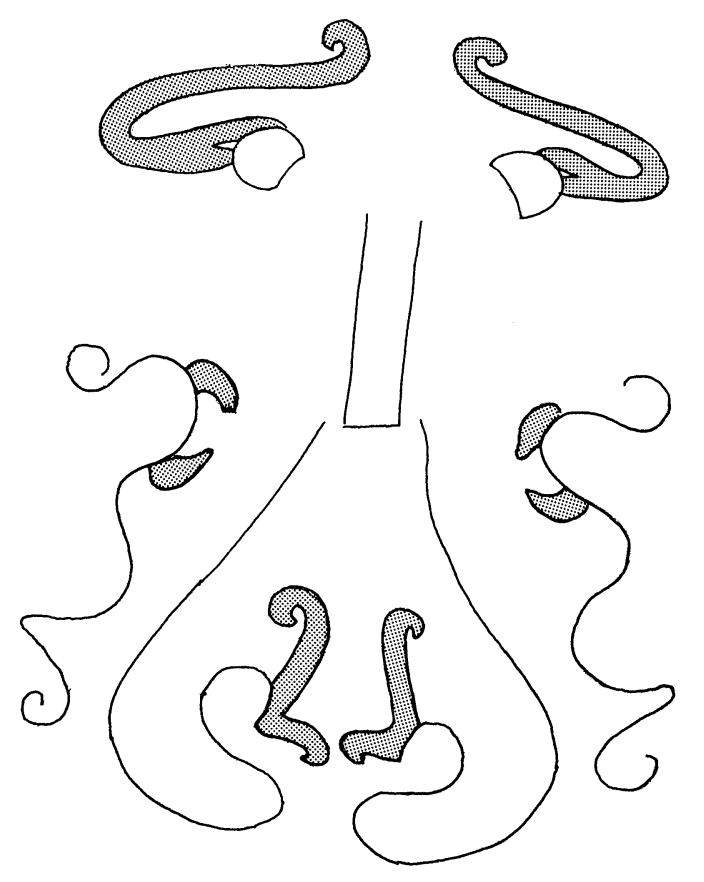

Figure 7. Use of the color brown in figure 1 design. Drawing: Mary Helms. 


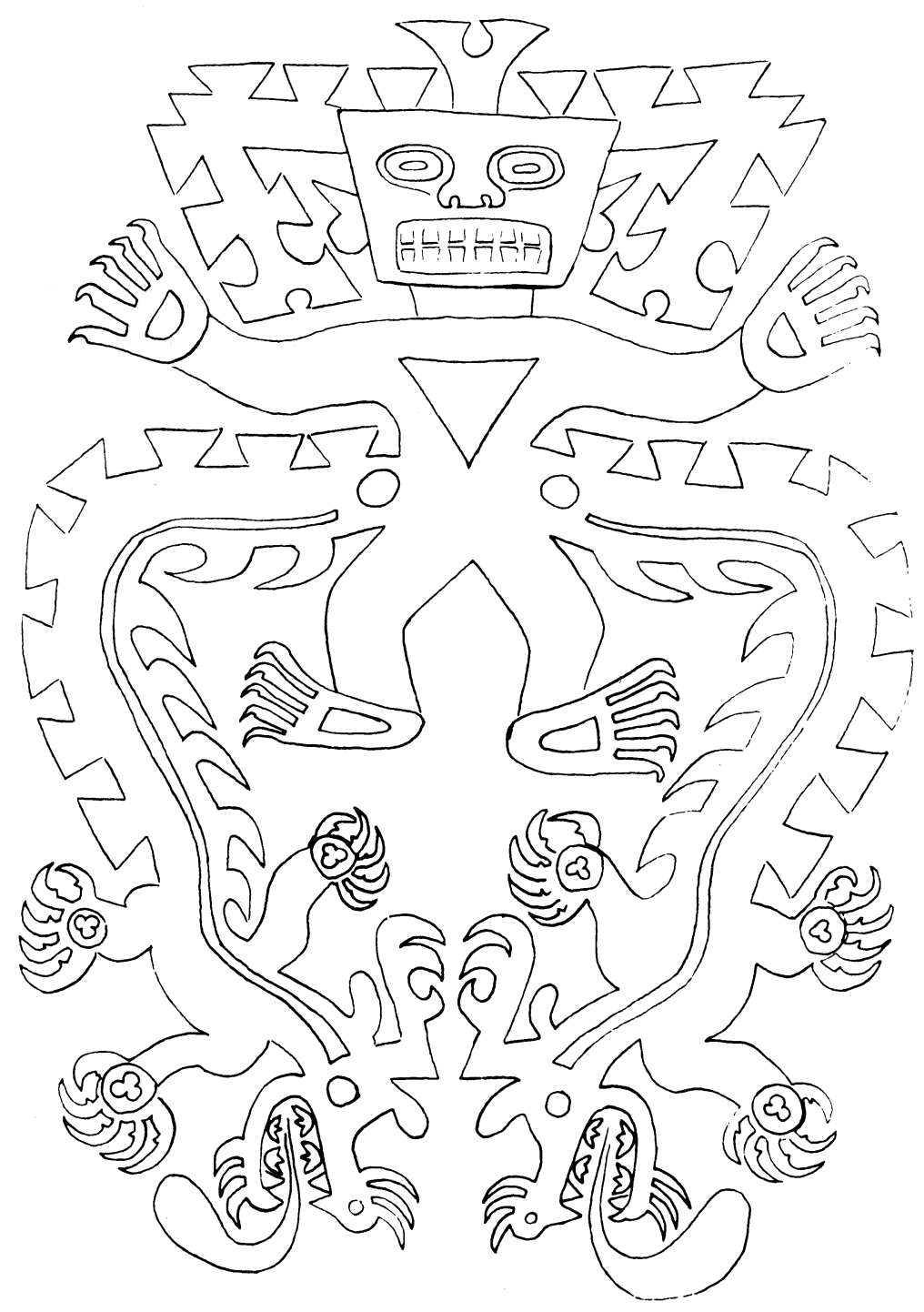

Figure 8. Embossed gold chestplate, Sitio Conte, Panama, A.D. 700-900. $26.0 \times 18.1 \mathrm{~cm}$. University of Pennsylvania Museum Object \#40-13-26. Courtesy of the University Museum, University of Pennsylvania. Drawing: Mary W. Helms.

far as design composition and the explicit depiction of a creature with side animals attached are concerned, even though the side animals are not affixed to the waist but emanate from the ends of the upper limbs of the central figure. (Note that although on each side the "arm" and "leg" of the central figure are depicted by a single curvilinear [serpentine] flow of line, a distinction is made between upper and lower limbs through the color of the "flares" that emanate from these lines.
Those flares identifying the upper limbs are in brown; those of the lower limbs are in red.) ${ }^{7}$

7. Panamanian art is full of depictions of points or "flares," often roughly triangular in shape, emanating in outline fashion from body parts or positioned in geometric designs. What these design motifs "mean" is open to question. They may have been used to indicate concepts of "radiance" or luminosity or perhaps emanations of supernatural power. What these design motifs "are" in physical terms if, in fact, they have any physical prototype or manifestation at all, is 


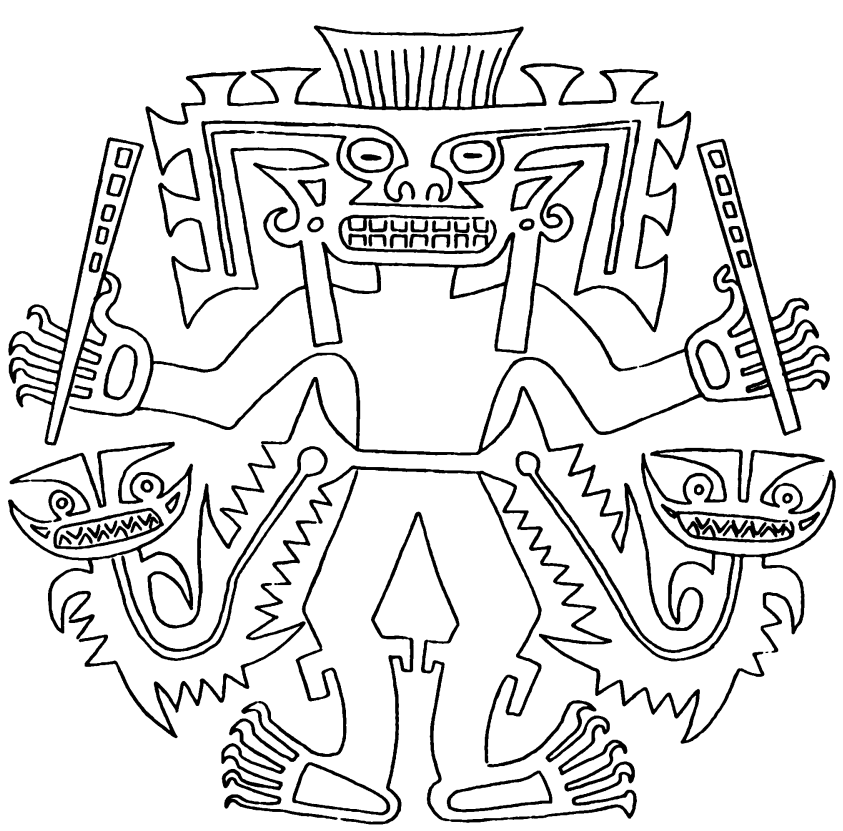

Figure 9. Embossed gold chestplate, Sitio Conte, Panama, A.D. 700-900. $20.6 \times 20.8 \mathrm{~cm}$. University of Pennsylvania Museum Object \#40-13-3. Courtesy of the University Museum, University of Pennsylvania. Drawing: Mary W. Helms.

In contrast with the possibly chiefly (see $n .8$ ) belted hunters depicted on the chestplates, which are neutral in gender, ${ }^{8}$ the central creature in figure 1 is portrayed as distinctly female, as are a number of other depictions of frontal, open-armed, bipedally standing, head-crested beings in Panamanian ceramic art (Lothrop 1976:16 [lower right], 25, 28 [top left], 42 [left], 91 [top]) (see fig. 11). This identification brings to mind themes of a supernatural Mother found among contemporary indigenous peoples of lower Central America and adjacent northern South America, such as the Kuna (Panama) concepts of Great Mother (wife of Great Father) and the "grandmother" spirit known as Muu and the Kogi (Colombia) concept of the Great Mother. The Kuna Great Mother, associated with the earth, worked with Great Father to create the world, while Muu is

also problematical, but one possibility, suggested by the shapes frequently accorded their depictions, is that they were modeled after shark teeth. Shark teeth could also be referenced by V-elements discussed below (see Borhegyi 1961:pl. 1 and text).

8. Francis Huxley, discussing the Urubu Indians of northern Brazil, describes beliefs that their culture hero, Maír, who, like a chief, is also responsible for ultimate social and moral order, has little, if any, overt sexuality when in his chiefly role (1995:160-161).
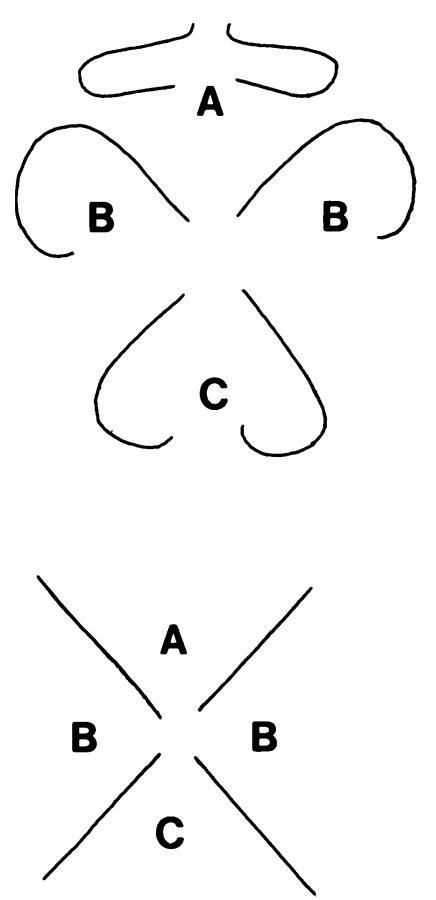

Figure 10. Quadripartite organization of figure 1. Drawing: Mary Helms.

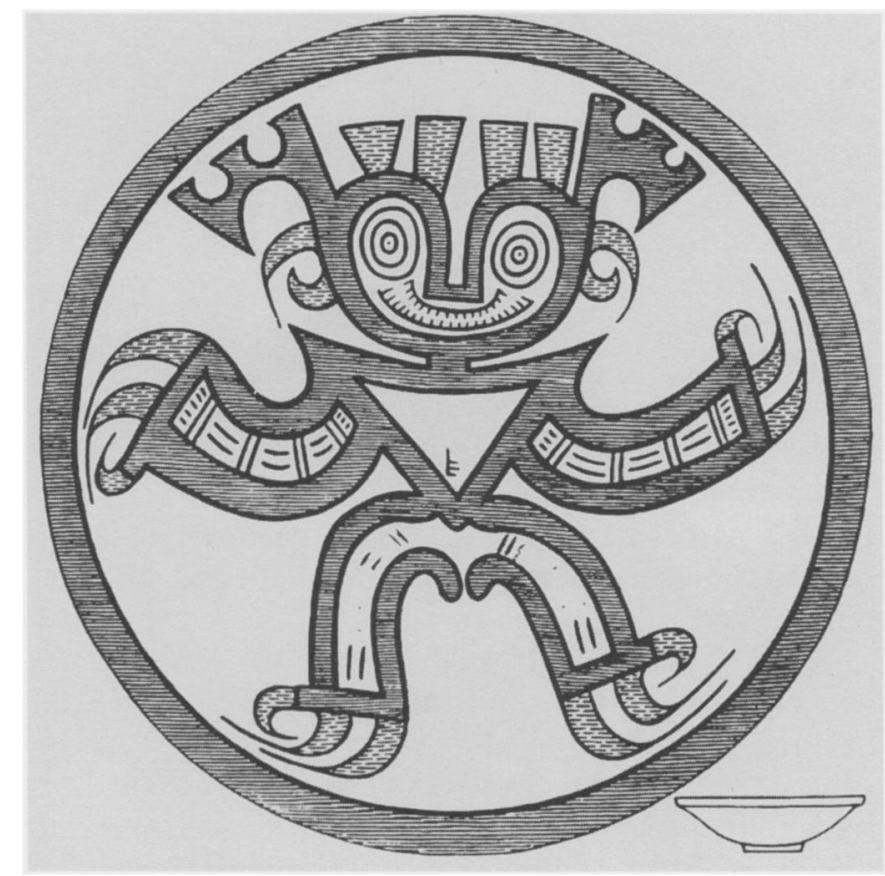

Figure 11. Four-limbed, upright-stanced, female-gendered being. From Samuel K. Lothrop, Pre-Columbian Designs From Panama (Dover Publications, 1976), p. 25 (lower left). Courtesy of Dover Publications. 


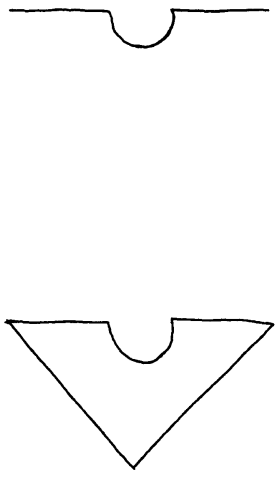

b
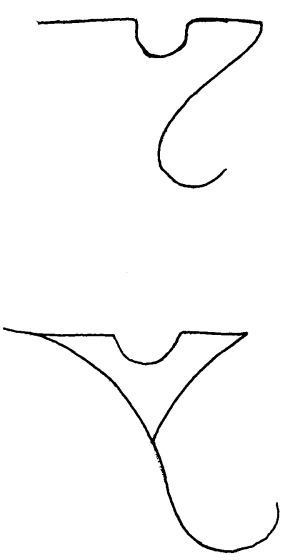

C
Figure 12. Y- and V-element design forms. (a) lines with gaps; (b) basic V-element; (c) basic Y-element. Drawing: Mary Helms.

responsible more specifically for the formation of human souls and fetuses, regulates childbirth, and at birth predetermines the events and actions of each person's life. The Kogi also identify the Great Mother as creator of the universe (interpreted by the Kogi with metaphors referring to the uterus and womb) and of humankind and as provider of good harvests, good health, and protection against evil. In addition, all animal spirits and the doubles of all humans dwell at Great Mother's sacred mountain, essentially identifying the Kogi Great Mother as Mistress of Animals, too (Howe 1974:115; 1986:36, 68, 283, n. 3; Lévi-Strauss 1979; Nordenskiöld 1979:372-374, 385-386, 437-438; Reichel-Dolmatoff 1974:297; 1978:13-14, 21, 24-25). In short, these female-gendered supernatural representations seem to be responsible not for the maintenance of life via the acquisition of game animals and social and moral order, which are the responsibility of the supernatural hunter-cum-culture hero, but for the creative processes of fertility and birth that originally produced and continue to produce essential plant, human, and animal life forms.

Let us turn to the red and black side mammals, which may represent game animals imbued with the quality of serpentness. These animals are linked to the central figure's lower limbs and "feet" by the black serpentine lines of its "arms." These "feet" are portrayed as profiled heads whose open mouths create the identifying female genitalia. In other words, each side mammal (head and body) constitutes one end of a serpentine continuum (the arm-leg line) that terminates in another head. This dualism illustrates the theme of the double-headed serpent, a motif depicted in a variety of ways in Panamanian art (and widespread in the Americas) that apparently references the concept of the serpent as a long, undifferentiated length of body whose head-end and tail-end are comparable though not necessarily identical (Helms 1995:chaps. 2, 7).

The open black mouth of the central figure (combined with the blackness of the serpentine limbs) indicates that the main figure is qualitatively serpentine, too. The paired "feet" at the end of the serpent continuum (that is, the profiled heads of the lower limbs), which together also create another type of "open mouth," can be seen as forming a "base" for the design that is paired with the serpentine "head-end." Therefore, the basic serpent motif of "head-end corresponds with tail-end" (for example, both head and base feature bodily orifices) can also be applied to the central figure.

Head-end-tail-end serpentine associations in figure 1 are also expressed by means of a kenning that is ubiquitous in Panamanian art. This so-called "Yelement" (sometimes portrayed as a " $\mathrm{V}$ "-element) is created by drawing a line in such a way as to create a dip or gap in its continuity (fig. 12). This basic design, which may be modified and developed in many ways, may also refer to the serpent theme (see also n. 7) perhaps by reflecting the coiled form of the serpent or referring to the connectedness of a head-end, a central body line, and a tail-end (Helms 1995:30 35).

On figure 2 it is clear that the continuous curvilinear black line that on each side composes the arm-leg length of the central figure is, in fact, drawn as a Yelement (fig. 13a) with the gap depicted as composing part of the central body form of the main creature and the emanating lengths of line composing arms and legs, respectively. Closer examination also reveals that the tips of each of the arm and leg lines also end in small Yelements adjacent to each open mouth (fig. 13a, detail). In comparable fashion, though perhaps less immediately obvious to the viewer, the overall composition formed by the two black arm-leg serpent lines composing the two side-animals and the "base" section of the main design can be seen as a single, large Y-element (fig. 13b) in which the "gap" is formed by the profiled base heads with open mouths that delineate female genitalia, while the side animals define the two "ends" of the overall serpentine length. ${ }^{9}$

9. Figure $13 \mathrm{~b}$ further suggests that the serpentine "arms" holding game animals could also be associated with breasts and the suckling of young-another way of referring to the male-female relationship or duality that imbues this design overall The widespread twin motif conceivably could be involved, too. 

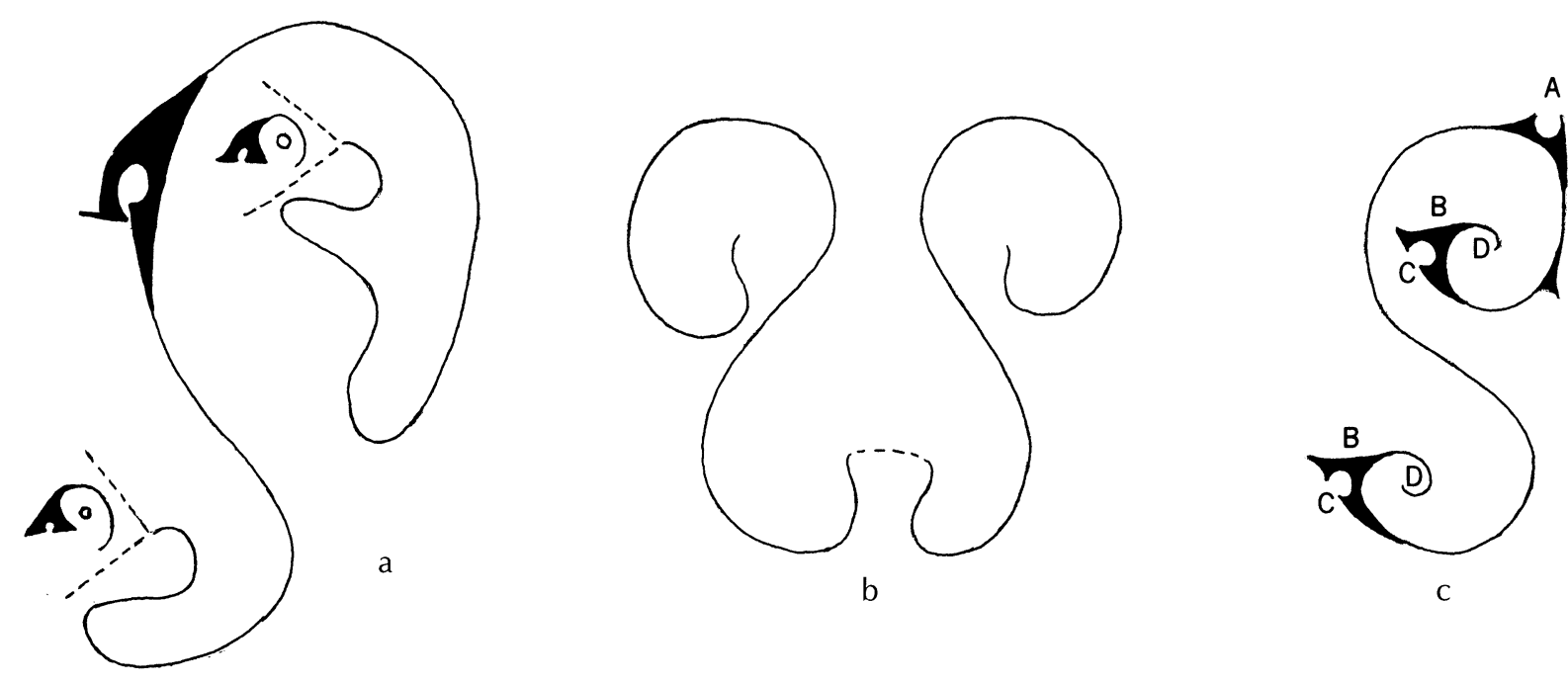

Figure 13. Y-elements used in the composition of figure 1. (a) Single arm-leg line as Y-element. Details show an additional small V-element at each end of the arm-leg line; (b) Y-element composed of both arm-leg serpent lines; (c) Internal organs portrayed as composite of Y-elements including gap (A) of main Y-element with ends of main lines (B) portrayed as profiled heads with headcrests (D). Drawing: Mary Helms.

A somewhat more complicated serpentine Y-element is also used to depict the "center" or (more likely) internal reproductive organs of the main figure (fig. 13c). This Y-element is a composite of a central "gap" (A on fig. 13c) with two lengths attached, each of which is depicted as ending in a profiled head (B) with a crest. Each of these crested heads in turn is also depicted as a Y-element in which the gap (C) forms the head and the line (D) forms the crest. This method of presenting internal organs by means of Y-elements is not uncommon in Panamanian art (for example, Labbé 1995:figs. 30, 43, 56; Lothrop 1976:45 [bottom], 58 [bottom left], 101 [lower right], 104 [top left]). In addition to addressing the specific theme of reproduction, it may refer to the general importance of "that which is within," a basic theme of indigenous Panamanian symbolism and metaphor still expressed today among the Kuna in various artistic and communicative media (Helms 1981:4-6; 1995:77-78, 91). ${ }^{10}$ Within the context of the overall design format of figure 1, seen as composed of four quarters, this kenning also may be intended to identify the "center," a fundamental concept which the Kogi (among many other peoples) recognize as crucial to their view of the

10. This motif is found in the use of pre-Columbian mise-encouleur metallurgical techniques, in forms of political oratory mentioned in early Spanish descriptions and used by contemporary Kuna, and in the construction and sewing techniques used by Kuna women in creating the well-known mola panels. universe, which is perceived not only in terms of uterus and womb but also as having a quadripartite form with a central focal point, a perception which also refers to the human body (Reichel-Dolmatoff 1978).

With respect to the use of Y-elements in design styles, it is also interesting to note that on the depictions of the side animals in figure 2, the shape of the open mouths (red) takes the form of V-elements which are virtually identical to the curves of the creatures' tails (red). This use of identical kennings to delineate mouths and tails can be seen as yet another example of the common stylistic device of equating head-end with tail-end when depicting serpent-related body forms.

Consideration of the thematic contexts expressed by figure 1 can also lead in other directions. There seems to be a gender duality in the central figure between a presumably male hero-hunter (implied by the side game animals) and a female being, suggesting the procreative power of a Great Mother (indicated by the profiled heads constituting the female genitalia at the base of the central figure). On each side of the central figure, however, the two creatures that signal this gender duality - the "arm" game animal and the "foot" profiled base head-are conjoined as two ends of a single serpent length. This suggests the essential complementarity of male and female roles with respect to the acquisition of food and reproductive sex for the continuation of life. Pursuing this approach from a somewhat different perspective, however, we can also 
see the two side animals as constituting two separate but identical forms ( $B$ and $B$ on fig. 10) each of which is independently linked by a serpent length to the single female-gendered base (C), suggesting a conjunction of several separate but identical "male" forms within a common theme of "female" reproduction.

It is conceivable that this imagery speaks to the sociopolitical relationships created by marriage alliances in which separate but structurally identical sons-in-law (Bs; like game animals, also derived from an Outside domain) are related to the reproductive social unity of the kin group or "house" by virtue of marriage to its women (C). This pattern also is in accord with ethnographic descriptions from lower Central America where, especially among the Kuna (but also to some extent among the Guaymí of Panama and the Talamancan peoples of southern Costa Rica), uxorilocal residence for daughters is still practiced. This residence pattern was documented for Panamanian Indians in the seventeenth century (Wafer 1934:xviii-ix) and may well be pre-Columbian in origin. In these settings, sons-inlaw generally have been seen as providers for their wife's households (Bozzoli de Wille 1975:40; Holloman 1976; Young 1971:173). When the head-end of figure 1 (A on fig. 10) is added to this interpretation, we may posit a reference to the male authority figure of the house or kin group, the central power figure to whom both daughters and sons-in-law (connected to each other in figure 1 by the shared arm-leg serpent lines) are made social appendages (note the connection of the $Y$ element gap of the arm-leg serpent line to the neck end of the central head) to create a socially reproductive political-ideological unit. This unity is metaphorically depicted in figure 1 in terms of the constituent "pieces" of the human body.

This relationship may be seen, too, in the relationship of part $A$ to part $C$ in figure 10; that is, the two segments of the overall quadripartite design (in contrast to B and B) are not separate-though-identical in design form but rather are different-thoughcomplementary in design form. The segments are also directly connected to each other by way of the center of the overall design in contrast to the side animals (Bs) that, strictly speaking, are not themselves directly connected to the center of the overall design (note that their feet do not touch anything). The crux of this different-but-connected complementarity of $\mathrm{A}$ and $\mathrm{C}$ may be encoded in the use of the color brown to identify both the female gender of the base of the central figure and the eye-streamers that seem to approximate the form of (and thus may represent) a headdress for the central figure (compare figs. 8-9, 11). As was suggested before in somewhat different terms regarding metaphorical connections between things that gleam, glisten, or flash (that is, eyes and illumination connected to reproductive organs and processes), brown as used in figure 1 (see figs. 2, 7) can be postulated to signal the conjoining of female fertility and reproduction with male political-ideological authority, the latter represented now by the symbolism of a headdress. ${ }^{11}$

Combining all four sections of the design of figure 1-A, B, B, C (fig. 10)-we may postulate a succinct statement regarding the sociopolitical organization of the kin group or "house" as comprised of reproductive women and their spouses under the general authority of a male kin group head. As is common in traditional societies (Eliade 1959:95), this dynamic and ejuvenating world of social reproduction and political leadership is expressed in and legitimated by archetypes that refer to cosmological themes and personages. In the wonderfully multivalent imagery of figure 1 , the human roles and social relationships that constitute the "family" (or, by extension, the polity) are expressed and grounded in imagery that seems to invoke a cosmological Great Mother (perhaps with additional connotations of Mistress of Animals) and a gamebearing hero-hunter-cum-Great Father (possibly also implying a Master of Animals). All these mythical or metaphorical beings and relationships, in turn, are further depicted as manifestations of an even more fundamental cosmological power that is contained in the primordial Great Serpent itself-purest and most original expression of the fundamental dynamic that constitutes the very essence of life and imbues and interrelates all forms and manifestations of physical and social life.

11. The interested reader is invited to compare the imagery of figures 1, 8, and 9 with the figure in Lothrop (1976:42 [left]). Considered together, they suggest a continuum of emphasis which ranges from clear-cut belted-hunter imagery (fig. 9), to images combining the hunter theme (including strong side-animal representations) with various implications of female gendering (figs. 1 , 8), to imagery strongly favoring female gendering in which the sideanimals seem to be portrayed in embryonic form as offspring of female sexuality (Lothrop 1976:42 [left]; see also $n .9$ above). See also Helms (n.d.) for discussion of a possible zoological correlate for the central figure other than the boa that is especially appropriate for figures 8 and 9 and Lothrop (1976:42 [left]). 


\section{BIBLIOGRAPHY}

Borhegyi, Stephen F. de

1961 "Shark Teeth, Stingray Spines, and Shark-Fishing in Ancient Mexico and Central America." The Southwestern Journal of Anthropology 17:273-296.

Bozzoli de Wille, Maria E.

1975 "Birth and Death in the Belief System of the Bribri Indians of Costa Rica." Ph.D. diss., University of Georgia, Athens.

Cooke, Richard G.

1984 "Archaeological Research in Central and Eastern Panama: A Review of Some Problems," in The Archaeology of Lower Central America, ed. Frederick W. Lange and Doris Z. Stone, pp. 263-302. University of New Mexico Press, Albuquerque.

1985 "Ancient Painted Pottery from Central Panama." Archaeology 38:33-39.

Eliade, Mircea

1959 Cosmos and History. Harper \& Bros., New York.

Helms, Mary W.

1977 "Iguanas and Crocodilians in Tropical American Mythology and Iconography with Special Reference to Panama." Journal of Latin American Lore 3:51-132.

1979 Ancient Panama. University of Texas Press, Austin.

1981 Cuna Molas and Coclé Art Forms. Institute for the Study of Human Issues, Philadelphia.

1992 "Cosmovision of the Chiefdoms of the Isthmus of Panama," in The Ancient Americas: Art from Sacred Landscapes, ed. Richard F. Townsend, pp. 217-227. The Art Institute of Chicago, Chicago.

1995 Creations of the Rainbow Serpent: Polychrome Ceramic Designs from Ancient Panama. University of New Mexico Press, Albuquerque.

n.d. "The Spectacled Bear in Iconic Imagery of Ancient Panama and Colombia." In preparation.

Holloman, Regina E.

1976 "Cuna Household Types and the Domestic Cycle," in Frontier Adaptations in Lower Central America, ed. Mary W. Helms and Franklin O. Loveland, pp. 131149. Institute for the Study of Human Issues, Philadelphia.

Howe, James

1974 "Village Political Organization among the San Blas Cuna." Ph.D. diss., University of Pennsylvania.

1986 The Kuna Gathering: Contemporary Village Politics in Panama. University of Texas Press, Austin.
Huxley, Francis

1995 Affable Savages (1956). Sheffield Publishing Co., Salem, Wisconsin.

Kensinger, Kenneth $M$.

1991 "Feathers Make Us Beautiful: The Meaning of Cashinahua Feather Headdresses," in The Gift of Birds, ed. Ruben E. Reina and Kenneth M. Kensinger, pp. 40-49. University Museum of Archaeology and Anthropology, University of Pennsylvania, Philadelphia.

Labbé, Armand J.

1995 Guardians of the Life Stream: Shamans, Art and Power in Prehispanic Central Panama. The Cultural . Arts Press, The Bowers Museum of Cultural Art, Santa Ana, California.

Lévi-Strauss, Claude

1969 The Raw and The Cooked. Harper \& Row, New York.

1979 "The Effectiveness of Symbols," in Reader in Comparative Religion, 4th ed., ed. William A. Lessa and Evon Z. Vogt, pp. 318-327. Harper \& Row, New York.

Linares, Olga F.

1977 Ecology and the Arts in Panama: On the Development of Social Rank and Symbolism in the Central Provinces. Dumbarton Oaks Studies in PreColumbian Art and Archaeology 17. Dumbarton Oaks, Washington, D. C.

Lothrop, Samuel K.

1942 Coclé: An Archaeological Study of Central Panama. Part II, Pottery of the Sitio Conte and Other Archaeological Sites. Memoirs of the Peabody Museum of Archaeology and Ethnology, vol. VIII. Harvard University, Cambridge.

1976 Pre-Columbian Designs from Panama: 591 Illustrations of Coclé Pottery. Dover Publications, New York.

$\rightarrow$ Morphy, Howard

1989 "From Dull to Brilliant: The Aesthetics of Spiritual Power among the Yolngu." Man 24:21-40.

Nordenskiöld, Erland

1979 An Historical and Ethnological Survey of the Cuna Indians (1925), ed. Henry Wassén. AMS Press, New York. 
Rabineau, Phyllis

1975 "Artists and Leaders: The Social Context of Creativity in a Tropical Forest Culture," in The Cashinahua of Eastern Peru, ed. Kenneth M. Kensinger et al., pp. 87-109. Haffenreffer Museum of Anthropology, Brown University, Providence, Rhode Island.

Reichel-Dolmatoff, Gerardo

1974 "Funerary Customs and Religious Symbolism Among the Kogi," in Native South Americans, ed. Patricia J. Lyons, pp. 289-301. Little, Brown and Co., Boston.

1978 "The Loom of Life: A Kogi Principle of Integration." Journal of Latin American Lore 4:5-27

Roe, Peter G.

1989 "Of Rainbow Dragons and the Origins of Designs: The Waiwai and the Shipibo Ronin Ehua." Latin American Indian Literatures Journal 5:1-67.

Schele, Linda, and Mary Ellen Miller

1986 The Blood of Kings. George Braziller, Inc., New York.

Stone, Doris

1962 The Talamancan Tribes of Costa Rica. Papers of the Peabody Museum of Archaeology and Ethnology, vol. 42. Harvard University, Cambridge.

Wafer, Lionel

1934 A New Voyage and Description of the Isthmus of America (1699), ed. L. E. Elliott Joyce. Series II, vol. 73. The Hakluyt Society, Oxford.

Whitten, Dorothea S., and Norman E. Whitten, Jr.

1988 From Myth to Creation. University of Illinois Press, Urbana.

Young, Philip D.

1971 Ngawbe: Tradition and Change among the Western Guaymi of Panama. University of Illinois Press, Urbana. 